\title{
The influence of structure on deformation and failure in clay soil
}

BARDEN, L. (1972). Géotechnique 22, No. 1, 159-163.

\section{K. S. Sankaran and R. Bhaskaran, Indian Institute of Technology, Madras-36, India}

The Author has given arguments supporting the idea that the behaviour of clays and sand is similar. This discussion pertains only to the aspect of anisotropic strength response of clays.

It appears that the Author associates strength and deformation behaviour of clays with the preferred orientation of clays. The Writers believe that strength anisotropy of cohesive soils is not only a function of preferred orientation of particles but also of the stress history and have shown that anisotropy in undrained strength of a kaolinite clay varies with the overconsolidation ratio and is therefore tied up with the stress conditions experienced by the sample during one-dimensional compression, besides being influenced by the fabric anisotropy (Sankaran and Bhaskaran, 1972a). Hansen and Gibson (1949) and Duncan and Seed (1966a) have shown in theory that even if the soil is isotropic in its physical properties, it may exhibit anisotropic strength response if subjected to a one-dimensional stress condition.

The Author has used the observation of Ingles and Lee (1971) to support his analysis. It may be pointed out that Ingles and Lee have characterized the anisotropic response of soils by doing strength tests on vertical and horizontal samples. The Writers feel that strength anisotropy cannot be truly characterized unless at least an inclined specimen is tested besides the vertical and horizontal specimens (Sankaran and Bhaskaran, 1972b).

Duncan and Seed (1966a) and Khera (1967) have observed that isotropic re-consolidation affects the anisotropic strength response of the soil samples initially prepared by one-dimensional compression (initial anisotropic stress condition). The Writers have noted similar observations in their preliminary investigations. It is felt that isotropic re-compression applied to one-dimensionally consolidated specimens to determine effective stress strength parameters, imparts a new stress history as well as alters the fabric, consequently altering the anisotropic response of the soil specimens. Barden has concluded that the effective stress strength parameters are isotropic for anisotropic soils based on Bishop et al. (1965) and Barden (1971). However, there is evidence in literature (Duncan and Seed, 1966b; Skempton and Hutchinson, 1969) to show that effective stress parameters are not isotropic for anisotropic soils. The difference in the nature of the effective stress parameters is a function of the anisotropy in terms of fabric and stress history, as mentioned earlier. Therefore, it is suggested that one must be cautious in generalizing the anisotropic response of clays and more so in generalizing the anisotropic strength response of clays and sands.

\section{REFERENCES}

Barden, L. (1971). Examples of clay structure and its influence on engineering behaviour. Roscoe Memorial Symposium, Cambridge.

Bishop, A. W., Webb, D. L. \& Lewin, P. I. (1965). Undisturbed samples of London clay from the Ashford common shaft: strength-effective stress relationships. Géotechnique 15, No. 1, 1-30.

Duncan, J. M. \& Seed, H. B. (1966a). Anisotropy and stress reorientation in clays. Jnl Soil Mech. Fodns Div. Am. Soc. Civ. Engrs 92, SM5, 21-50.

Duncan, J. M. \& Seed, H. B. (1966b). Strength variation along failure surfaces in clay. Jnl Soil Mech. Fdns Div. Am. Soc. Civ. Engrs 92, SM6, 81-104. 
Hansen, J. B. \& Gibson, R. E. (1949). Undrained shear strength of anisotropically consolidated clays, Géotechnique 1, No. 3, 189-204.

Ingles, O. G. \& Lee, I. K. (1971). The influence of initial grain shape and pore anisotropy on strength of brittle soils. Géotechnique 21, No. 2, 143-153.

Khera, R. P. (1967). Strength response of anisotropically consolidated clays. PhD thesis, Western University, Illinois.

Sankaran, K. S. \& Bhaskaran, R. (1972a). Strength anisotropy in cohesive soils. To be published in Proc. Symp. Modern Trends in Civil Engineering 1, Roorkee, Oct.

Sankaran, K. S. \& Bhaskaran, R. (1972b) Private communication.

Skempton, A. W. \& Hutchinson, J. (1969). Stability of natural slopes and embankment foundation, State of art report, 7th Int. Conf. Soil Mech., Mexico. State of art volume, 308-332.

\section{The consolidation of soils exhibiting creep under constant effective stress}

GARLANGER, J. E. (1972). Géotechnique 22, No. 1, 71-78.

\section{Suklje, University of Ljubljana, Yugoslavia}

Based on the soil model described by Bjerrum (1967), Garlanger has expressed the void ratio change corresponding to an increase of effective pressures from $p_{0}$ to $\sigma^{\prime}$, according to the strain path OAB when $\sigma^{\prime} \leqslant p_{\mathrm{c}}$, and OCDE when $\sigma^{\prime} \geqslant p_{\mathrm{c}}$ (Fig. 1). In the latter case, at a time $t$ after the end $\left(t_{\mathrm{i}}\right)$ of the increase of effective stress up to $p_{\mathrm{f}}$, the void ratio change has been presented by the equation

$$
\frac{e}{e_{0}}=\left(\frac{p_{\mathrm{c}}}{p_{0}}\right)^{-a}\left(\frac{p_{\mathrm{f}}}{p_{\mathrm{c}}}\right)^{-b}\left(\frac{t_{\mathrm{i}}+t}{t_{1}}\right)^{-c}
$$

$a$ and $b$ being the respective slopes of the lines $\mathrm{OC}$ and $\mathrm{CD}$. Garlanger considers that the stress $p_{\mathrm{f}}=p$ is a time dependent variable. Consequently

$$
\frac{\partial e}{\partial t}=\frac{\partial e}{\partial p} \frac{\partial p}{\partial t}+\left(\frac{\partial e}{\partial t}\right)_{c}
$$

where

$$
\frac{\partial e}{\partial p}=\frac{b e}{p}
$$

and

$$
-\left(\frac{\partial e}{\partial t}\right)_{\mathrm{c}}=\left(\frac{c e}{t_{\mathrm{i}}}\right)\left(\frac{e}{e_{\mathrm{c}}}\right)^{1 / c}\left(\frac{p}{p_{\mathrm{c}}}\right)^{b / c}
$$

with $p \equiv \sigma^{\prime}$ according to the notation in Fig. 1. When $p \leqslant p_{\mathrm{c}}$, equation (1) reduces to

$$
\frac{e}{e_{0}}=\left(\frac{p}{p_{0}}\right)^{-a}\left(\frac{t_{1}+t}{t_{1}}\right)^{-c}
$$

In this case, Garlanger has obtained

$$
-\frac{\partial e}{\partial p}=\frac{a e}{p}
$$

However, at $\sigma^{\prime} \leqslant p_{\mathrm{c}}$ the time $t_{\mathrm{i}}$ has to be considered a stress dependent parameter and so equation (3) is regained for $\partial e / \partial p$.

If one assumes a sudden cffective stress increase, the slope $a$ becomes zero and the strain paths $\mathrm{OAB}$ and OCDE have to be replaced by respective strain paths OFB and OGE (Fig. 1). 